1 Hacettepe Journal of Mathematics and Statistics

$\bigcap$ Volume 47 (6) (2018), 1742-1753

\title{
Research on the dynamic relationship between industrial structure adjustment and the development level of modern logistics industry
}

\author{
Jian Liu*, Shengsheng $\mathrm{Li}^{\dagger \dagger}$ and Yunlei Zhou ${ }^{\S}$
}

\begin{abstract}
In this paper we select the time series data of Jiangxi province of China in 1985-2014, and construct VECM model to analyze the influence of industrial structure adjustment on the development of modern logistics industry in Jiangxi province of China. The study has found that there is a stable long-term equilibrium relationship between the development level of logistics industry and the three industries in Jiangxi Province and each additional $1 \%$ of the primary industry accounted for the proportion of GDP, will cause the development level of the logistics industry increased by $1.445 \%$, each additional $1 \%$ of the second and third industry upgrade rate, will promote the development of the logistics industry increased by $11.508 \%$ and $4.166 \%$. We draw a conclusion that in the short term, there is a dynamic non-equilibrium relationship between the development level of logistics industry and industrial structure in Jiangxi Province, and the existence of error correction mechanism makes the non-equilibrium state in the short term tend to be balanced in the long run. The proportion of the added value of the first and second industries is the unidirectional Granger reason of the development level of the logistics industry in Jiangxi Province. In addition, the contribution rate of the first and second industries to the development level of logistics industry in Jiangxi province is larger, while the variance contribution rate of the third industry is small. Finally, this paper gives the corresponding policy recommendations.
\end{abstract}

Keywords: Industrial structure adjustment, modern logistics, VECM model

Received : 17.04.2017 Accepted : 28.06.2018 Doi : 10.15672/HJMS.2018.601

*School of Information Technology, Jiangxi University of Finance and Economics, Nanchang, People's Republic of China, Email: liujian3816@263.net

${ }^{\dagger}$ School of Information Technology, Jiangxi University of Finance and Economics, Nanchang, People's Republic of China, Email: lisheng2@f oxmail.com

$\ddagger_{\text {Corresponding Author. }}$

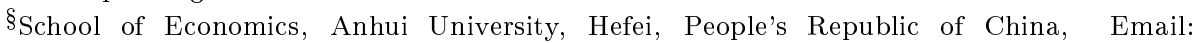
zhouleileiha@f oxmail.com 


\section{Introduction}

In recent years, the third industry of our country has been developing continuously, and the proportion of its value added to GDP has been more than the proportion of the industry of the second. The service industry has gradually occupied the leading position and become the trend of economic development in our country. Belong to the third industry logistics industry has constantly promoted the development of the third industry. So that the current logistics industry is closely related to China's economic development trend is particularly important. In the meantime, the logistics industry has linked with transport, packaging, loading and unloading, transportation, circulation processing, and other basic functions and integrated warehousing, transportation, information industry and other industries, while it has become a new complex industry [4]. Among them, Jiangxi Province, with the unique geographical location connecting north and south, the rapid development of its logistics industry, has initially formed a relatively complete logistics and transport infrastructure system. At the same time, the improvement of Internet communication level has promoted the development of modern logistics industry in Jiangxi Province. In 2014, the turnover of goods in Jiangxi Province reached 382.8 billion tons $/ \mathrm{km}$, an increase of $5.16 \%$ over the previous year. In the key stage of the development of the logistics industry, Jiangxi Province has continuously increased its investment in the logistics industry, and actively take measures to promote economic reform, and then adjust the economic structure. At the same time, the continuous adjustment of industrial structure to promote the optimization and upgrading of industrial structure, industrial restructuring can better promote the development of modern logistics industry, and the development of the logistics industry can continue to promote the optimization and upgrading of industrial structure, both interaction to promote the economic development of Jiangxi Province.

The adjustment of the industrial structure will bring about changes in the market circulation products, which will also affect the development of the logistics industry. The transportation industry is part of the modern logistics industry, and the adjustment of the industrial structure has a significant impact on the various modes of transportation of the transportation industry. Consequently, some scholars have studied the correlation between the structural structure and the structural characteristics of the transportation industry, for example, Yuping Wang [5] has carried on the quantitative analysis to the correlation between the structural characteristics and the industrial structure in the transportation industry, and analyzed the growth factors of various modes of transportation in the transportation industry, and his study found that the demand for goods is heavy industry and the impact of passenger transport demand is the tertiary industry. Some scholars have also studied the relevance of industrial restructuring and modern logistics,such as Linbang Fan [2] selects social logistics cost as the proportion of GDP to measure the level of development of modern logistics industry, and through constructing multiple linear regression model to analyze the influencing factors of social logistics cost, and draws a conclusion that there is no significant correlation between the level of economic development and logistics cost, however there is a significant correlation between industrial structure, technological development level and logistics cost. Meanwhile, Xiaobing Le [3] uses cointegration regression equation and grey relational analysis theory to study the relationship between modern logistics and industrial structure upgrading. The study finds that there is a long-term stable equilibrium relationship between the contribution rate of logistics and the upgrading rate of industrial structure, and the second industrial upgrading rate has a greater impact on modern logistics industry. Xiayue Chen [1] selects the southeast coastal provinces on behalf of the logistics industry development level and industrial structure indicators in 2006-2012. He constructs three fixed effect 
panel data model by selecting these indicators and empirical researches the influence of the development level of the modern logistics industry on the industrial structure, thus he indicates that changes in industrial structure have significant relevance to logistics efficiency, logistics supply and logistics demand, and last puts forward rationalization proposals.

In recent years, in Jiangxi Province, the proportion of the three major industries in GDP has changed a lot, but the proportion of the secondary industry is still more than $50 \%$, which still occupy the leading position in the economy, and the tertiary industry is only $35 \%$, both still far. Thus Jiangxi province has a large space for industrial restructuring. At the same time, the logistics industry in Jiangxi province has different development trend with the adjustment of industrial structure. Therefore, this paper analyzes the correlation between the industrial structure adjustment and the modern logistics industry by constructing the vector error correction model based on the previous scholars' research, and provides the reference suggestions for the development of the logistics industry in Jiangxi Province.

\section{Indicators and data in empirical research}

2.1. Setting of indicators. In the selection of indicators, there is no uniform standard in the statistical research in China at the current statistical research, so that different literature has different indicators to select the standard. Yongjian Wen et al. [6] has selected logistics infrastructure investment in fixed assets to measure the logistics infrastructure investment, and in this study he regarded the value of transportation, storage and post and telecommunications industry as the index of logistics industry output value, and selected the sum of water transport mileage and freight volume as the index to measure the logistics supply capacity and demand ability, which studies the differences in the development efficiency of logistics between different regions. Jiansheng Zhang [7] chooses freight turnover, land and sea airways and other five modes of transport and the total mileage of transport and post and telecommunications industry to represent the logistics needs, supply and scale indicators to study the development of the logistics industry and economic growth related relationship. Based on the previous research, this paper uses the factor analysis model to get the comprehensive score from the three aspects of logistics industry output value, demand and supply to measure the development level of Jiangxi modern logistics industry. The main indicators are as follows:

(1) Select transportation, warehousing and postal services added value (100 million yuan) to measure the logistics industry in Jiangxi Province, which denoted by $Y_{1}$.

(2) Select cargo turnover (100 million tons of kilometers) to measure the demand for logistics industry with $Y_{2}$.

(3) Choose highway, railway, inland waterway transport mileage of three modes of transport $(\mathrm{km})$ to measure the logistics industry supply capacity by $Y_{3}$.

(4) The analysis software SPSS 22 to $Y_{1}, Y_{2}$ and $Y_{3}$ variables were normalized after $Z Y_{1}, Z Y_{2}, Z Y_{3}$ by statistics, and carries on the comprehensive score of factor analysis to measure the level of development of the logistics industry in Jiangxi Province, represented by the letter $Y$.

In addition, with the letter $X_{1}, X_{2}, X_{3}$ represents the primary industry as the proportion of GDP, the proportion of secondary industry and the proportion of tertiary industry, which to measure the proportion of industrial structure changes.

2.2. Data selection and preliminary processing. In view of the availability of data, this paper chooses the time series data of Jiangxi Province from 1985 to 2014, and the selected data comes from "Jiangxi Province Statistical Yearbook 2015". In addition, in order to eliminate the influence of price changes on each variable, the time series data 
of each variable were reduced by the deflator (last year $=100$ ), and then the variables $X_{1}, X_{2}$ and $X_{3}$ to measure the change of industrial structure were taken Logarithm, and set the variable symbols to $L N X_{1}, L N X_{2}, L N X_{3}$. Factor analysis to measure the level of the logistics industry indicators, and the principal component method is used to extract the common factor according to the size of the eigenvalue and the contribution rate. The number of the extracted common factors is 2 , and the variance of the two common factors is obtained Contribution rate of $98.306 \%$, greater than $85 \%$, in line with the principle of extraction of public factors. Finally, the scores of two common factors are obtained by SPSS 22.0 statistical analysis software and the factor comprehensive score $Y$ is calculated by using the variance contribution rate of the common factor after rotation, where $Y=\left(50.106 * F_{1}+48.118 * F_{2}\right) / 98.224$. Factor scores and comprehensive scores are shown in Table 1.

Table 1. The level of development of the logistics industry factor score of Jiangxi Province

\begin{tabular}{cccccccccccc}
\hline Year & $F_{1}$ & $F_{2}$ & $Y$ & $Y e a r$ & $F_{1}$ & $F_{2}$ & $Y$ & $Y e a r$ & $F_{1}$ & $F_{2}$ & $Y$ \\
\hline 1985 & -0.559 & -0.718 & -0.64 & 1995 & -0.250 & -0.772 & -0.51 & 2005 & 0.013 & -0.036 & -0.01 \\
1986 & -0.518 & -0.745 & -0.63 & 1996 & -0.183 & -0.766 & -0.47 & 2006 & -1.874 & 2.667 & 0.35 \\
1987 & -0.482 & -0.769 & -0.62 & 1997 & -0.074 & -0.817 & -0.44 & 2007 & -1.768 & 2.692 & 0.42 \\
1988 & -0.459 & -0.771 & -0.61 & 1998 & 0.045 & -0.826 & -0.38 & 2008 & 0.248 & 1.242 & 0.74 \\
1989 & -0.458 & -0.757 & -0.60 & 1999 & 0.119 & -0.827 & $\mathrm{e}-0.34$ & 2009 & 0.268 & 1.297 & 0.77 \\
1990 & -0.476 & -0.729 & -0.60 & 2000 & -0.327 & -0.015 & $\mathrm{e}-0.17$ & 2010 & 0.887 & 0.986 & 0.94 \\
1991 & -0.482 & -0.722 & -0.60 & 2001 & -0.448 & 0.124 & -0.17 & 2011 & 1.245 & 0.936 & 1.09 \\
1992 & -0.452 & -0.722 & -0.58 & 2002 & -0.302 & 0.077 & -0.12 & 2012 & 2.071 & 0.607 & 1.35 \\
1993 & -0.380 & -0.759 & -0.57 & 2003 & -0.203 & 0.043 & -0.08 & 2013 & 2.416 & 0.466 & 1.46 \\
1994 & -0.312 & -0.772 & -0.54 & 2004 & 0.037 & -0.026 & 0.01 & 2014 & 2.659 & 0.411 & 1.56 \\
\hline
\end{tabular}

\section{Analysis on the dynamic relationship between industrial struc- ture adjustment and modern logistics development}

3.1. Data smoothness test. Due to the unique characteristics of economic data, the selected data may be non-stationary. If the model contains non-stationary economic variables, the model may be spurious regression model, therefore, using the ADF unit root test method to select the time series data for unit root test, and select the sequence of smoothness. This paper uses the measurement software Eviews8.0 to carry out the unit root test. The test results are shown in Table 2. From Table 2, we can see that the absolute value of the ADF statistic of the original sequence of the development level of logistics industry in Jiangxi Province $(Y)$, the proportion of primary industry added value to GDP $\left(L N X_{1}\right)$, the proportion of secondary industry added value to GDP $\left(L N X_{2}\right)$ and the proportion of tertiary industry added value to GDP $\left(L N X_{3}\right)$ is less than the absolute value of the critical value below the $5 \%$ level. This indicates that the original sequence at $95 \%$ confidence level is non-stationary. Therefore, the $Y, L N X_{1}, L N X_{2}$ and $L N X_{3}$ need to be further differential and then the unit root test. It is found that the absolute value of the $\mathrm{ADF}$ statistic value of the difference sequence is greater than the absolute value of the critical value of $5 \%$, and the corresponding concomitant probability is less than 0.05. In conclusion, the sequences $D Y, L N X_{1}, L N X_{2}$ and $L N X_{3}$ are stationary time series. Therefore, the time series in this paper are all $I(1)$. 
Table 2. Unit toot test results

\begin{tabular}{lccccl}
\hline Variable & Test Type $^{\mathrm{a}}$ & $\begin{array}{c}\mathrm{ADF} \\
\text { Statistics }\end{array}$ & $\begin{array}{c}\text { Critical } \\
\text { Value }(0.05)\end{array}$ & $\begin{array}{c}\text { Concomitant } \\
\text { Probability P }\end{array}$ & Conclusion \\
\hline$Y$ & $(c, T, 0)$ & -0.057500 & -3.580623 & 0.9950 & nonstationary \\
$D Y$ & $(c, T, 1)$ & -8.386170 & -3.580623 & 0.0000 & stationary \\
$L N X_{1}$ & $(c, T, 0)$ & -3.266127 & -3.595026 & 0.0942 & nonstationary \\
$D L N X_{1}$ & $(c, T, 1)$ & -5.056224 & -3.595026 & 0.0021 & stationary \\
$L N X_{2}$ & $(c, T, 0)$ & -2.457018 & -3.580623 & 0.3450 & nonstationary \\
$D L N X_{2}$ & $(0,0,1)$ & -3.726032 & -1.953381 & 0.0006 & stationary \\
$L N X_{3}$ & $(c, T, 0)$ & -2.158943 & -3.595026 & 0.4911 & nonstationary \\
$D L N X_{3}$ & $(0,0,1)$ & -2.417336 & -1.955020 & 0.0179 & stationary \\
\hline
\end{tabular}

$(c, T, d)$ represents the intercept, time trend and lag order contained in the tested equation, respectively; and $D(Y)$ represents the first order difference of $Y$.

3.2. Cointegration test between variables. The above time series $Y, L N X_{1}, L N X_{2}$, $L N X_{3}$ are integrated of order one $I(1)$, the linear combination between them may be a stationary time series, that is, there is a long-term stable equilibrium between the variables. In this paper, the cointegration test method proposed by Johansen and Juselius is used to test the cointegration relationship between variables. This paper chooses the annual data, and obtains the information standard with order lag order of 1 to 4 , and selects the AIC, SC, LR, FPE, HQ and other information criteria as the criteria for choosing the optimal lag order, and choose from the principle of the majority to determine the optimal lag order of cointegration analysis. The statistical results are shown in Table 3.

Table 3. Optimal hysteresis order table for each information criterion

\begin{tabular}{ccccccc}
\hline Lag & LogL & LR & FPE & AIC & SC & HQ \\
\hline 0 & 88.86670 & NA & $1.72 \mathrm{e}-08$ & -6.528210 & -6.33465 & -6.47247 \\
1 & 202.95600 & 184.29800 & $9.26 \mathrm{e}-12$ & -14.07354 & -13.10577 & -13.79485 \\
2 & 230.55210 & $36.08729^{*}$ & $4.19 \mathrm{e}-12^{*}$ & -14.96555 & $-13.22357^{*}$ & -14.46392 \\
3 & 244.95830 & 14.40617 & $6.24 \mathrm{e}-12$ & -14.84295 & -12.32675 & -14.11837 \\
4 & 273.07180 & 19.46322 & $4.62 \mathrm{e}-12$ & $-15.77476^{*}$ & -12.48435 & $-14.82724^{*}$ \\
\hline
\end{tabular}

* indicates the optimal hysteresis order selected under an information criterion.

It can be seen from Table 3 that the optimal lag order of AIC and HQ criterion is 5, and the optimal lag order determined by LR, FPE and SC criterion is 2, so according to the majority rule,and the optimal lag of the model is determined according to the criterion of the majority , and finally determine the optimal lag order of the model is 2 , so the order of the cointegration test is 1 . Then, we perform the cointegration test with a lag order of 1 , and get the test results are shown in Table 4. 
Table 4. JJ cointegration test results

\begin{tabular}{|c|c|c|c|c|c|c|c|c|c|}
\hline & $\begin{array}{c}\text { Null } \\
\text { Hypothesis }\end{array}$ & $\begin{array}{c}\text { Trace } \\
\text { Statistic }\end{array}$ & $\begin{array}{c}0.05 \text { Critical } \\
\text { Value }\end{array}$ & Pro.** & & $\begin{array}{c}\text { NULL } \\
\text { Hypothesis }\end{array}$ & $\begin{array}{c}\text { Trace } \\
\text { S Statistic }\end{array}$ & $\begin{array}{c}0.05 \text { Critical } \\
\text { Value }\end{array}$ & Pro." \\
\hline Trace & None* & 82.00407 & 47.85613 & 0.000 & Max- & None* & 47.24087 & 27.58434 & $\overline{0.000}$ \\
\hline Statistic & At most $1^{*}$ & 34.76320 & 29.79707 & 0.012 & Eigen & At most $1^{*}$ & * 26.90179 & 21.13162 & 0.007 \\
\hline Test & At most 2 & 7.86141 & 15.49471 & 0.480 & Statistic & At most 2 & 6.79888 & 14.26460 & 0.513 \\
\hline
\end{tabular}

* denotes rejection of the hypothesis at the 0.05 level, ${ }^{* *}$ Mackinnon-Haug-Michelis(1999) p-values.

As can be seen from Table 4, based on the test results of the trace statistics and the test results based on the maximum eigenvalue, when the null hypothesis is "there is no cointegration relationship between the variables(None)", the corresponding concomitant probability is 0 , less than 0.05 , which rejects the null hypothesis. This shows that there is a long-term stable dynamic equilibrium relationship between the development level of logistics industry and industrial structure in Jiangxi province. From the test results in the further observation can be obtained when the null hypothesis is" there is a cointegration relationship at most between variables(At most 1)", the statistics based on the trace test and the maximum eigenvalue are 34.76320 and 26.90179 , respectively, which are more than the critical value of the significant level of $5 \%$. This indicates that the covariance test rejects the null hypothesis. When the null hypothesis is "there are two cointegration relationships at most between variables(At most 2)", the statistics based on the trace test and the maximum eigenvalue are 7.86141 and 6.79888 respectively, which are less than the critical value of the significant level of $5 \%$, and the corresponding concomitant probability is $0.480,0.513$, were greater than 0.05 , so it passes the test. Therefore, there are two cointegration relationship between the level of logistics development and the structure of the three major industries at the significance level of $5 \%$. This explains that there is a long-term stable equilibrium relationship between the development level of logistics industry and industrial structure in Jiangxi province. The cointegration equation is,

$$
Y=1.455 L N X_{1}+11.508 L N X_{2}+4.166 L N X_{3}
$$

From the cointegration equation, we can see that there is a long-term stable equilibrium relationship between the development level of logistics industry and industrial structure in Jiangxi province. There is a positive correlation between the level of development of the logistics industry and the three major industries. Each additional 1\% of the primary industry accounted for the proportion of GDP, will cause the development level of the logistics industry increased by $1.445 \%$, each additional $1 \%$ of the second and third industry upgrade rate, will promote the development of the logistics industry increased by $11.508 \%$ and $4.166 \%$. This denotes that the rationalization of industrial structure can promote the improvement of the level of logistics industry.

3.3. Granger causality test. Granger causality can be used to test whether there is an impact between variables and whether there is a relationship in the economic sense. Accordingly, the use of Granger causality test to determine the level of development of the logistics industry and the relationship between the industrial structure. The test results are shown in Table 5. 
Table 5. Granger causality test results

\begin{tabular}{cccccc}
\hline $\begin{array}{c}\text { Null } \\
\text { Hypothesis }\end{array}$ & F-Statistic & Prob. & $\begin{array}{c}\text { Null } \\
\text { Hypothesis }\end{array}$ & F-Statistic & Prob. \\
\hline$L N X_{1}$ does not Granger Cause $Y$ & 5.51371 & $0.0111^{*}$ & $L N X_{2}$ does not Granger Cause $L N X_{1}$ & 1.65431 & 0.2132 \\
$Y$ does not Granger Cause $L N X_{1}$ & 0.26198 & 0.7718 & $L N X_{1}$ does not Granger Cause $L N X_{2}$ & 5.58234 & $0.0106^{*}$ \\
$L N X_{2}$ does not Granger Cause $Y$ & 4.21830 & $0.0275^{*}$ & $L N X_{3}$ does not Granger Cause $L N X_{1}$ & 1.29907 & 0.2921 \\
$Y$ does not Granger Cause $L N X_{2}$ & 1.23218 & 0.3102 & $L N X_{1}$ does not Granger Cause $L N X_{3}$ & 0.74767 & 0.4846 \\
$L N X_{3}$ does not Granger Cause $Y$ & 0.36410 & 0.6988 & $L N X_{3}$ does not Granger Cause $L N X_{2}$ & 3.48288 & $0.0477^{*}$ \\
$Y$ does not Granger Cause $L N X_{3}$ & 0.13620 & 0.8734 & $L N X_{2}$ does not Granger Cause $L N X_{3}$ & 1.21354 & 0.3155 \\
\hline
\end{tabular}

* denotes rejection of the hypothesis at the 0.05 level.

From Table 5, it can be deduced that $p=0.0111<0.05$, when the null hypothesis is " $L N X_{1}$ does not Granger Cause $Y$ ", indicating that the original hypothesis is rejected at a significant level of $5 \%$, also implicitly indicating that the added value of the first industry accounting for the proportion of GDP in Jiangxi Province is the Granger cause of the development level of the logistics industry. Similarly, it can be concluded that the proportion of added value of GDP in the secondary industry in Jiangxi Province is the Granger cause of the development level of the logistics industry, and the proportion of added value of primary industry to GDP is the Granger cause of the proportion of GDP of the secondary industry, and the proportion of the added value of the tertiary industry in GDP is the Granger cause of the proportion of the second industry. In addition, all accept the original hypothesis, that is, the first and second industries is unidirectional Granger reasons of the level of development of the logistics industry, and the first and third industries is unidirectional Granger reasons of the second industry. However, there is no Granger causality between the remaining variables. This shows that the first and second industry changes can cause changes in the level of development of the logistics industry, the first and third industry changes can cause changes in the secondary industry, otherwise it is not.

3.4. VECM model estimation and testing. Cointegration test results show that there is a stable long-term equilibrium relationship between the level of development of logistics industry and industrial structure in Jiangxi Province. However, this relationship is only a long-term trend and will change in the short term. When this equilibrium is affected, the relationship between them will deviate from this equilibrium relationship. In general, in order to maintain this equilibrium relationship, it is necessary to establish the necessary correction mechanism to amend. Therefore, we establish the vector error correction model (VECM) to study the short-term relationship between the development level of logistics industry and the structure in Jiangxi province. The vector error correction model is a model with a cointegration constraint variable, which is the first order difference form of the unconstrained VAR model. It can be seen from Table 3 that the optimal lag order of the VAR model is 2 order, thus we construct the $\operatorname{VECM}(1)$ model. Also, we know that the unit root of the model is located within the unit circle from Figure 1 and the $\operatorname{VECM}(1)$ model satisfies the stability condition. 
nverse Roots of AR Characteris tic Polynomial

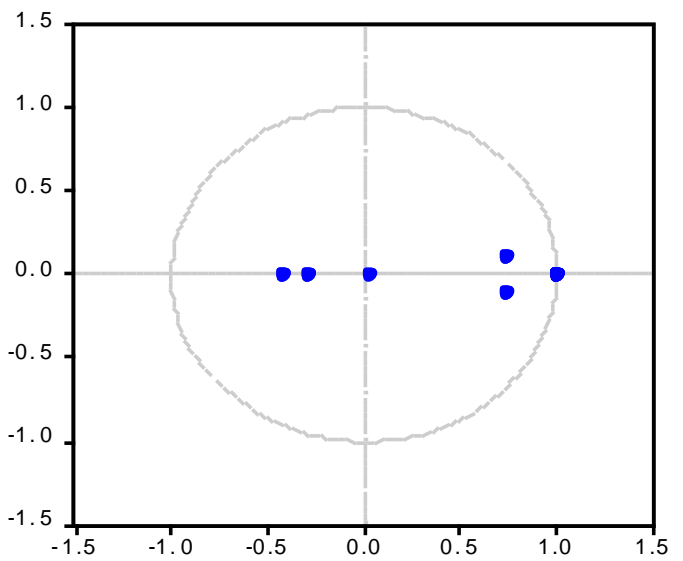

Figure 1. VECM model stationary test results

In order to discuss the influence of industrial structure on the development level of logistics industry in Jiangxi Province, the error correction model of Jiangxi Province's logistics development level is obtained by Eviews8.0. The model's $R^{2}$ is 0.669 and the adjusted model's $R^{2}$ is 0.593 more than 0.5 , indicating that the model is expected to be better.

The error adjustment is,

$$
E C M_{t}=Y-1.445 L N X_{1}-11.508 L N X_{2}-4.166 L N X_{3}-17.073
$$

and the VECM (1) model of the development level of the logistics industry is,

$$
\begin{aligned}
D Y_{t}= & -0.074 E C M_{t-1}-0.555 D Y_{t-1}-1.430 D\left(L N X_{1}\right)_{t-1} \\
& -1.985 D\left(L N X_{2}\right)_{t-1}-0.773 D\left(L N X_{3}\right)_{t-1}+0.094 .
\end{aligned}
$$

According to the results of the error correction model estimation of the development level of the logistics industry, the adjustment coefficient of the error correction term is -0.074 , which is less than 0 , which conforms to the reverse correction mechanism, indicating that when the system deviates from the long-term equilibrium state in the short term, will be $(-0.074)$ the adjustment of the non-equilibrium state back to equilibrium. In addition, the short-term dynamic fluctuation of the development level of the logistics industry is significantly related to the fluctuation of the first, second and third industries and its own fluctuation, and the adjustment coefficient is negative, which shows that the co-integration equation is effective, also indicates that the development of logistics industry is restricted by the long-term equilibrium relationship between the three major industries in the short term.

3.5. Impulse response analysis. Impulse response function is often used to consider the disturbance of a variable when the changes in their own and other variables in the system, can be more comprehensive reflection of the dynamic impact between the various variables. In this paper, the $\operatorname{VECM}(1)$ model is stable, so we can get the impulse response function analysis diagram of $L N X_{1}, L N X_{2}, L N X_{3}, Y$ in our province's logistics industry (Figure 2). The horizontal axis in Figure 2 indicates the number of hysteresis (unit: year), and the vertical axis represents the magnitude of the impact. From the figure we can see the following information: 
1. The development level of the logistics industry began to decline from the initial value of 0.063 and reached the minimum value of 0.019 in the second period, and then began to rise slowly, reaching the maximum value of 0.068 in the tenth period. It can be concluded that the development level of the logistics industry in Jiangxi province is a positive impact on itself, and it is stable after its own impact.

2. To the $L N X_{1}$ a standard deviation of the impact of the logistics industry development level from the initial value of 0 has been declining to the 10 th period to reach the minimum -0.122. This shows that the fluctuations in the proportion of the first industry value added to the negative impact of the province's logistics industry development level.

3. To the $L N X_{2}$ a standard deviation of the impact of the logistics industry development level from the initial value of 0 after a brief small fluctuations in the second period to reach the minimum -0.011 , then through the 0 axis, starting from the third period 0.002 has been rising, And reached a maximum of 0.119 in the tenth period. This shows that the fluctuations in the proportion of the value added of the second industry has a positive impact on the development level of the logistics industry in our province from the third period, and this positive impact is growing.

4. To the $L N X_{3}$ a standard deviation of the impact of the province's logistics industry development level fluctuations are not too large, has been around the 0 axis in the vicinity. This shows that the fluctuations in the value of the third industry accounted for less impact on the development of the logistics industry, and has remained stable.

Response of YtoY

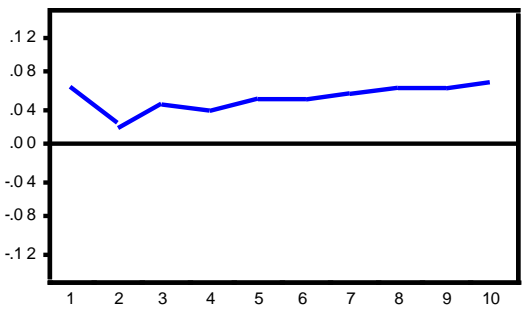

Resp on s e of Y to LNX2

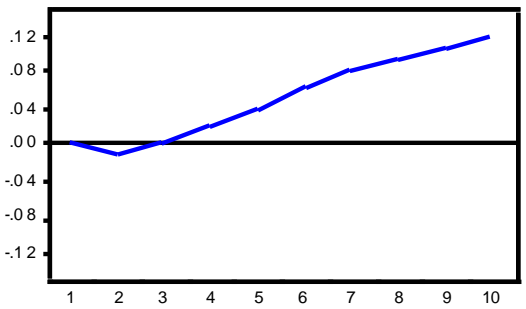

Res ponse of $Y$ to $L N X$

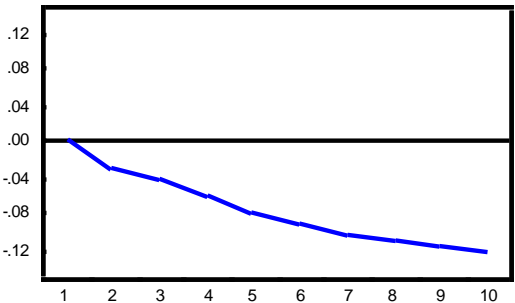

Res ponse of $Y$ to $L N X_{3}$

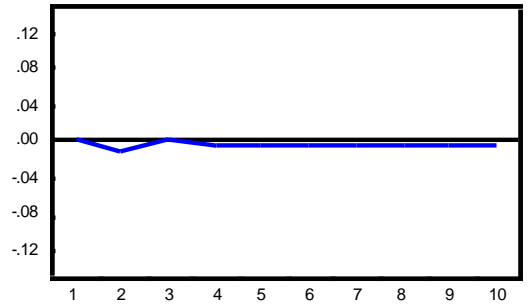

Figure 2. Impulse response function analysis

3.6. Variance decomposition analysis. Variance decomposition is the importance of assessing the impact of different structures by analyzing the extent to which each structural impact affects the endogenous variable. According to the vector error correction model constructed in this paper, the variance decomposition result chart is established for the development level of logistics industry in Jiangxi province (Figure 3). In Figure3, 
the horizontal axis represents the number of hysteresis (unit: year), and the vertical axis represents the contribution rate of a variable to the fluctuation of another variable. It can be seen from Figure 3 that with the increase of the number of periods, the variation variance of the development level of the logistics industry gradually declines in the part of the change of the self-change, while the proportion of the $L N X_{1}$ variance to the development level of the logistics industry gradually increases from the initial value of 0 began to rise in the sixth period reached a maximum of $51.401 \%$, after the basic stability of about $50 \%$. The proportion of added value of $L N X_{2}$ to the development level of the logistics industry increased from the initial value of 0 and there was a rising trend. The contribution rate of $L N X_{3}$ to the development level of the logistics industry is small, starting from the initial value of 0 , reaching the maximum value of $1.105 \%$ in the second period, then starting to decline and stabilizing near the 0 axis. To sum up, in the early stage, the variance of the development level of the logistics industry is explained by its own changes. In the later period, the variance of the development level of the logistics industry is mainly explained by the proportion of the added value of the first and the second industry, followed by its own changes, and the contribution rate of the variance of the added value of the tertiary industry is the smallest, which is consistent with the Granger causality test and impulse response analysis.

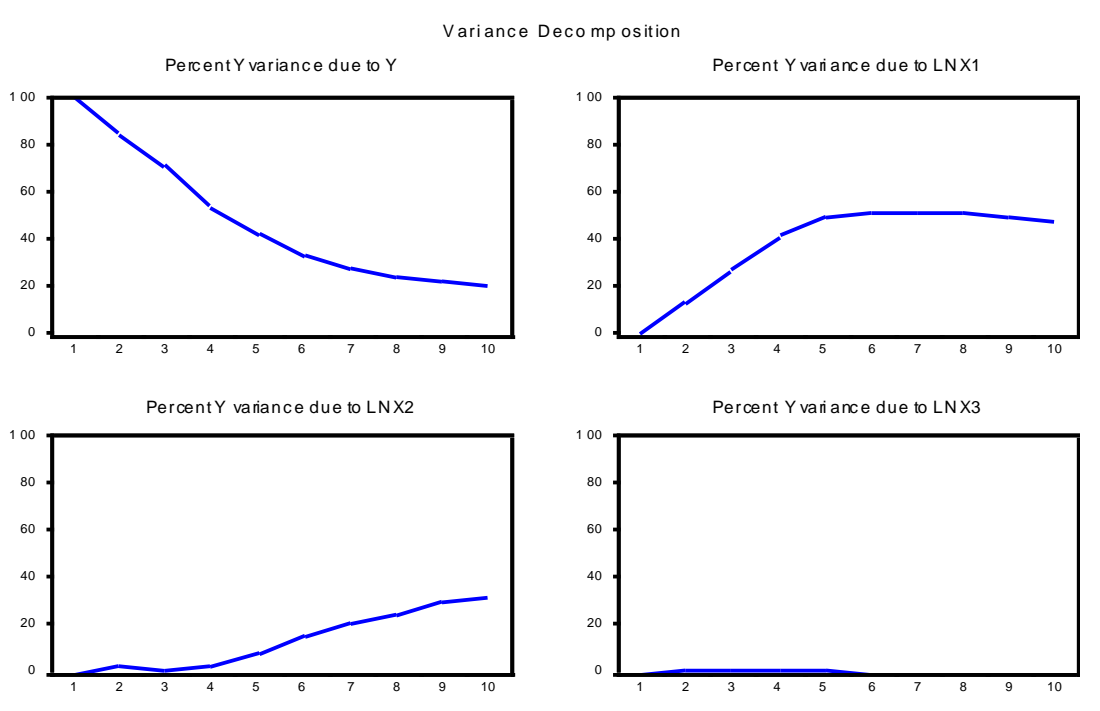

Figure 3. Analysis result of variance decomposition

\section{Discussion and conclusion}

In this paper, we establish the vector error correction model by using the time data of logistics industry development level and industrial structure in Jiangxi province from 1985 to 2014, and study the dynamic relationship between industrial structure adjustment and the development level of logistics industry in Jiangxi Province by cointegration analysis, Granger causality test, error correction model estimation, impulse response analysis and variance decomposition analysis. We draw the following conclusions:

(1) Through the cointegration analysis and the error correction model, there is a stable long-term equilibrium relationship between the development level of the logistics industry 
in Jiangxi Province and the three major industries. The proportion of the first industry in GDP will increase the development level of the logistics industry $1.445 \%$, each additional $1 \%$ of the second and tertiary industry upgrade rate, will be to promote the development of the logistics industry increased by $11.508 \%$ and $4.166 \%$. Therefore, in the long run, the increase of the proportion of the three major industrial industries in GDP can promote the development of the logistics industry in our province, among which the promotion of the secondary industry is the biggest, followed by the tertiary industry and the primary industry. In the short term, there is a dynamic non-equilibrium relationship between the development level of logistics industry and the industrial structure in Jiangxi Province. The adjustment coefficient of the error correction model is negative and conforms to the reverse correction mechanism, which can make the development level of the logistics industry and the three major industries in the long-term in a balanced state.

(2) Granger causality test shows that the first and second industrial added value ratio is unidirectional Granger reasons of the level of development of the logistics industry, which indicates that the development of the first and second industries in Jiangxi Province can promote the development level of the logistics industry. This conclusion is consistent with the fact that our province is located in the central and western regions and the economic development is mainly based on industry and agriculture. In addition, the first and third industries are the second industry Granger reasons, the first and third industry changes can lead to changes in the secondary industry.

(3) Through the impulse response analysis, the proportion of the second industry added value $L N X_{2}$ and the development level of the logistics industry $Y$ fluctuated a standard deviation, which have a positive impact on the development level of the logistics industry, while the impact of the tertiary industry on the development level of the logistics industry is relatively small, the first industry has brought negative impact. The variance decomposition results illustrates that the contribution rate of the variance of the first and second industries to the development level of the logistics industry is relatively large, while the variance contribution rate of the tertiary industry is small. In general, the first and second industries have a greater impact on the development of the logistics industry, especially the secondary industry and the development level of the logistics industry is more significant.

Due to the above conclusions, this paper puts forward some suggestions for the dynamic relationship between the development level of logistics industry and the industrial structure:

(1) Adjusting agricultural industrial structure and establishing modern agricultural logistics system. Jiangxi Province is located in the less developed areas of the central and western regions, agriculture still occupies a more important position, adjust the agricultural industry structure, promote the healthy development of agriculture and other primary industries, so as to improve the agricultural logistics system, and then promote the development of the secondary industry to promote its optimal upgrade. For example, improve the logistics system before agricultural production, promote the intensive operation of seed companies, pesticide companies, fertilizer companies and agricultural production equipment companies to improve efficiency, reduce agricultural production costs and promote agricultural development. Furthermore, improve the agricultural production logistics system. And improve the circulation of agricultural products, agricultural production waste logistics system. In the process of sales and transportation of agricultural products, it is necessary to improve the technology of storage and preservation of agricultural products so as to reduce transportation costs and risks.

(2) Promote the industrial and manufacturing industries to optimize and upgrade the secondary industry structure, and establish an industrial logistics system that adapts to the new-type industrialization. And to change the industrial, manufacturing and other 
enterprises independent of the concept of logistics, and create the concept of logistics supply chain to promote industrial and enterprise logistics outsourcing business, so as to promote the logistics industry socialization, professional development. To plan the construction of eco-logistics park, improve the industrial enterprise order center, freight center, distribution center and other integrated construction.

(3) Vigorously develop the tertiary industry, information industry, and construct the socialization, specialization, information of modern logistics service system. Logistics industry is part of the tertiary industry, to vigorously develop the tertiary industry, information industry, information technology to promote industrialization, thus driving the optimization and upgrading of the secondary industry structure, thereby promoting the development of modern logistics industry level; the same time, Jiangxi province should strengthen the development of the logistics industry information platform to improve the quality of logistics services.

(4) Give full play to the powerful role of the provincial government, increase the logistics industry to support efforts. The government should strengthen the investment in the financing of the logistics industry, and support the development of some new industries such as logistics finance and logistics insurance. At the same time, the province should improve the logistics infrastructure and transportation construction, improve the efficiency of logistics and transportation and reduce the logistics operation cost.

Acknowledgments For this research, the first author (Jian Liu) was supported by both the National Natural Science Foundation of China under Grant No.71761015 and Humanity \& Social Sciences Research of Jiangxi Provincal University of China under Grant No.JC1514, and the second author (ShengSheng Li) was supported by Jiangxi University of Finance and Economics Eleventh Student Research Project of China under Grant No.XS16468. The authors are very grateful to the editor and two anonymous reviewers.

\section{References}

[1] Chen, X., The impact of industrial structure on the development of modern logistics industry- An empirical study based on panel data of six provinces along the southeast coast of China, Journal of Chongqing Jiaotong University (Social Sciences Edition) 14 (4), 24-27, 2013.

[2] Fan, L., Social logistics cost as a proportion of GDP factors, Finance \& Economics 68 (8), 88-96, 2014.

[3] Le, X., Modern logistics and industrial structure to upgrade the mechanism of correlation, Logistics Technology 33 (4), 198-200, 2013.

[4] Li, z., Li, X., Study on the Interactive Relationship between the Development of Logistics Industry and the Regional Economic Growth in Jiangxi Province, Enterprise Economy 37 (2), 138-142, 2016.

[5] Wang, Y., Quantitative analysis of the impact of industrial structure on the development of transportation industry, Management World 20 (6), 65-72, 2004.

[6] Wen, Y., Wang, Y., China's modern logistics industry development efficiency of regional differences empirical analysis, Statistics \& Decision 24 (20), 107-109, 2008.

[7] Zhang, J., Study on the relationship between logistics development and economic growth based on VAR model, Railway Transport \& Economy 33 (20), 64-68, 2011. 